Title: Electronic Diamond: Fabrication Processes and Electron Emission Performance

Author(s):

Marion Scott, MST-7

Robert Springer, MST-7

Submitted to:

DOE Office of Scientific and Technical Information (OSTI)

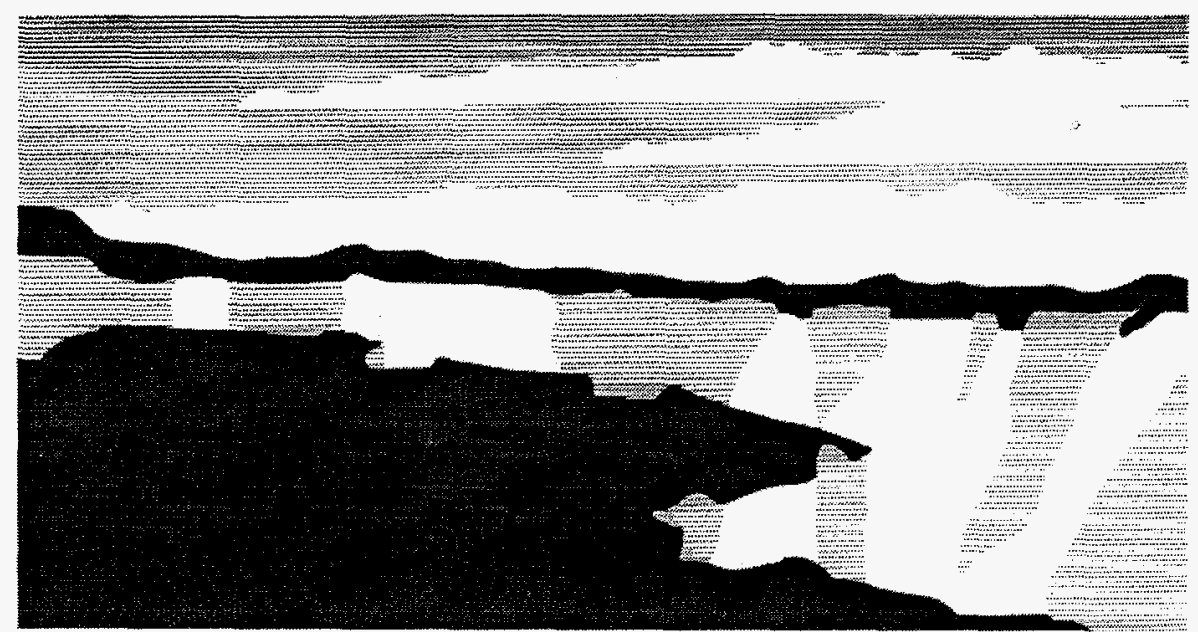

Los Alamos National Laboratory, an affirmative action/equal opportunity employer, is operated by the University of Calitornia for the U.S. Department of Energy under contract W-7405-ENG-36. By acceptance of this article, the publisher recognizes that the U.S. Government retains a nonexclusive, royaltyfree license to publish or reproduce the published form of this contribution, or to allow others to do so, for U.S. Government purposes. The Los Alamos National Laboratory requests that the publisher identify this anticle as work performed under the auspices of the U.S. Department of Energy. 


\section{Electronic Diamond: Fabrication Processes and Electron Emission Performance}

Marion Scott* and Robert Springer

Abstract
RECEIVED

SEP 231996

This is the final report of a one-year, Laboratory-Directed Research and 097 Development (LDRD) project at the Los Alamos National Laboratory (LANL). The project sought to develop a working Laboratory prototype model that would demonstrate the viability of a mercury-free light bulb concept in a controlled laboratory setting.

\section{Background and Research Objectives}

This LDRD project was instituted to perform research, in collaboration with DuPont, in the area of electron emissive materials and their applications. Originally, we intended to pursue a flat panel display application of this emissive technology, but the invention of a new type of fluorescent light bulb at LANL, with a coinventor at DuPont, based on these emissive materials, has led us in a different direction. DuPont has chosen not to pursue this light bulb technology with LANL. This light bulb application could lead to the replacement of our present fluorescent light bulb technology, which is used worldwide, with a bulb that does not require the addition of mercury for efficient performance. The absence of mercury is highly desirable to prevent the yearly addition of tons of mercury to the landfills of the planet [1].

Our research objectives for this LDRD were to utilize LANL facilities and personnel to develop test bed devices and perform experiments and material measurements that would allow us to adequately pursue applications of electron emissive materials. A goal of the project was to develop a working laboratory prototype model that would demonstrate the viability of the mercury-free light bulb concept in a controlled laboratory setting.

\section{Importance to LANL's Science and Technology Base and National R\&D Needs}

This electron emissive technology is highly important to LANL's science and technology base due to the ubiquitous nature of electron emission devices and technology utilized at LANL in process development, experimentation, and scientific investigations. One of the techniques

\footnotetext{
* Principal investigator, e-mail: mlscott@lanl.gov
} 
used to develop an emissive surface layer is the use of the flow-through ion gun, developed at LANL and illustrated in Figure 1. Los Alamos core competencies such as nuclear weapons science and technology; nuclear science, plasmas, and beams; nuclear and advanced materials; as well as complex experimentation and measurements could all be positively affected by advances and applications of emissive materials. LANL technology areas such as vacuum science, surface analysis, physical vapor deposition, and many others utilize electron emissive materials and could benefit from a deeper understanding or new applications of these materials.

National R\&D needs will certainly be well served by our pursuit of the next generation of fluorescent light bulb technology. The current research in the United States on a replacement technology for mercury-based fluorescent bulbs is another form of fluorescent bulb utilizing a gas plasma. This gas plasma technology will exhibit lifetime problems due to ion erosion of the cathode. The new light bulb technology being developed at LANL, which relies on emissive materials, does not incorporate a plasma in order to operate and therefore, does not exhibit this ion-erosion failure mechanism.

\section{Scientific Approach and Results to Date}

Our scientific approach to the application of electron emissive materials to important technological applications has been to characterize the materials (see Figures $2 \& 3$ ), develop test beds for prototype experimentation, and to utilize existing technology, where possible, to allow device development to proceed with maximum speed. With this approach, we have sidestepped several time consuming issues (which can be pursued in the future or as part of other projects) such as the development of efficient, low-energy, cathodolumenescent phosphors, and efficient, compact power sources.

With this concentration on our immediate objective, we were able to progress to a working laboratory model of the new light bulb that was suitable for patent application on the concept. A video cassette tape of the operation of the light bulb was recorded, at LANL, and later shown to potential sponsors at the Department of Energy (Office of Basic Energy Sciences and the Program Manager for Energy Conservation), where it was well received.

\section{Reference}

1. Thaler, E.G., et al., "Measurement of Mercury Bound in the Glass Envelope during Operation of Fluorescent Lamps," J. Electrochem. Soc., 142, 1968 (1965). 


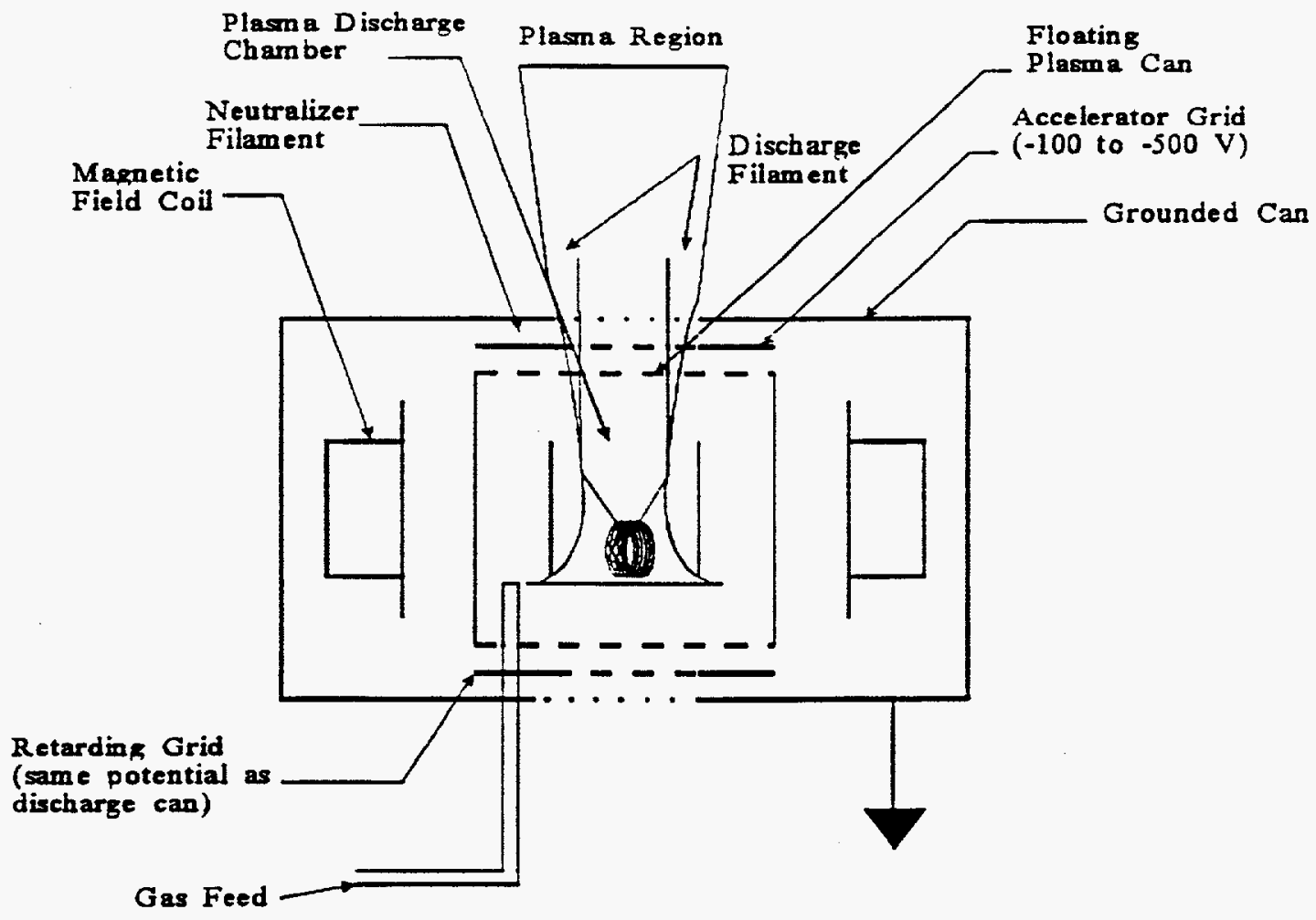

Figure 1. The flow-through ion gun has been utilized to energetically deposit materials with controlled structure in the deposited film. 


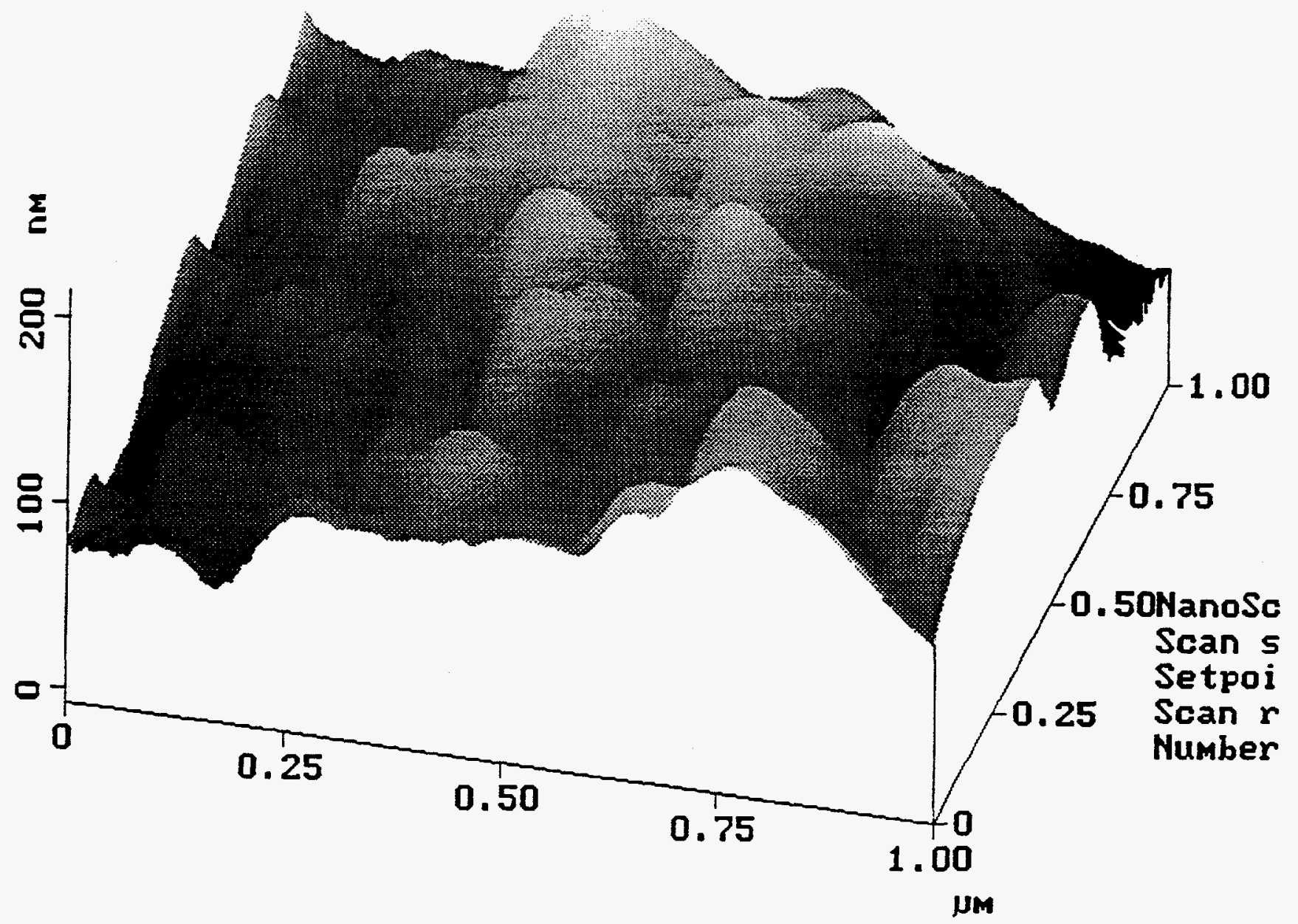

Figure 2. This atomic force microscope (AFM) micrograph illustrates the pointed structures that are typical of carbon surfaces treated to create an electron emissive surface. 


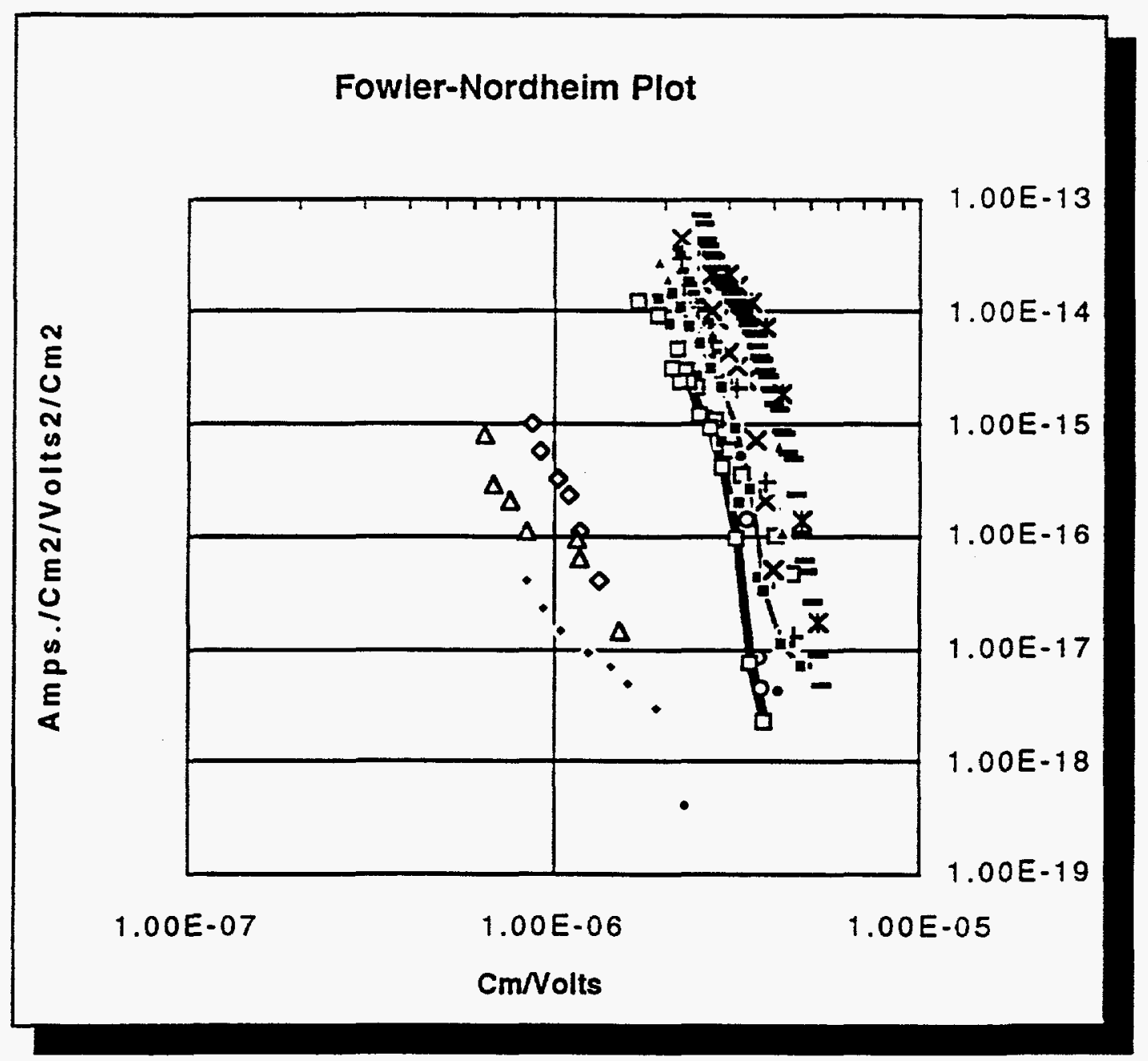

Figure 3. The Fowler-Nordheim plot of data generated for untreated materials (small group on the left) and treated carbon surfaces (large group on the right) indicates a large improvement in emission characteristics for the treated group over the untreated group. 


\section{DISCLAIMER}

Portions of this document may be illegible in electronic image products. Images are produced from the best available original document. 


\section{DISCLAIMER}

This report was prepared as an account of work sponsored by an agency of the United States Government. Neither the United States Government nor any agency thereof, nor any of their employees, makes any warranty, express or implied, or assumes any legal liability or responsibility for the accuracy, completeness, or usefulness of any information, apparatus, product, or process disclosed, or represents that its use would not infringe privately owned rights. Reference herein to any specific commercial product, process, or service by trade name, trademark, manufacturer, or otherwise does not necessarily constitute or imply its endorsement, recommendation, or favoring by the United States Government or any agency thereof. The views and opinions of authors expressed herein do not necessarily state or reflect those of the United States Government or any agency thereof. 